\title{
Cine Display Mode
}

National Cancer Institute

\section{Source}

National Cancer Institute. Cine Display Mode. NCI Thesaurus. Code C94870.

A display mode in which the object appears to move due to seeing views from sequentially slightly differing angles. This contrasts with the usual static image display and can assist in visual interpretation. 